\title{
Impact of national influenza vaccination strategy in severe influenza outcomes among the high-risk Portuguese population
}

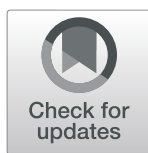

Ausenda Machado ${ }^{1,2^{*}}$ (D), Irina Kislaya ${ }^{1,2}$, Amparo Larrauri $^{3}$, Carlos Matias Dias ${ }^{1,2}$ and Baltazar Nunes $s^{1,2}$

\begin{abstract}
Background: All aged individuals with a chronic condition and those with 65 and more years are at increased risk of severe influenza post-infection complications. There is limited research on cases averted by the yearly vaccination programs in high-risk individuals. The objective was to estimate the impact of trivalent seasonal influenza vaccination on averted hospitalizations and death among the high-risk population in Portugal.

Methods: The impact of trivalent seasonal influenza vaccination was estimated using vaccine coverage, vaccine effectiveness and the number of influenza-related hospitalizations and deaths. The number of averted events (NAE), prevented fraction (PF) and number needed to vaccinate (NVN) were estimated for seasons 2014/15 to 2016/17.

Results: The vaccination strategy averted on average approximately 1833 hospitalizations and 383 deaths per season. Highest NAE was observed in the $\geq 65$ years population ( $85 \%$ of hospitalizations and $95 \%$ deaths) and in the 2016/17 season (1957 hospitalizations and 439 deaths). On average, seasonal vaccination prevented $21 \%$ of hospitalizations in the population aged 65 and more, and 18.5\% in the population with chronic conditions. The vaccination also prevented $29 \%$ and $19.5 \%$ of deaths in each group of the high-risk population. It would be needed to vaccinate 3360 high-risk individuals, to prevent one hospitalization and 60,471 high-risk individuals to prevent one death.

Conclusion: The yearly influenza vaccination campaigns had a sustained positive benefit for the high-risk population, reducing hospitalizations and deaths. These results can support public health plans toward increased vaccine coverage in high-risk groups.
\end{abstract}

\section{Background}

The annual circulation of influenza virus causes epidemics that can lead to a considerable burden of hospitalization and death, especially for a sub-group of the population with a high risk of influenza complications. It has been estimated that annually influenza is responsible for an excess of respiratory deaths that ranged from 4.0 to 8.8 per 100,000 worldwide, and these figures increased with age, causing an excess of 2.9 to 44.0 per 100000 individuals in the 65 to 74 age group [1]. In Portugal, influenza burden patterns are similar, and in

\footnotetext{
* Correspondence: ausenda.machado@insa.min-saude.pt

'Departamento de Epidemiologia, Instituto Nacional de Saúde Doutor Ricardo Jorge, Av. Padre Cruz, 1649-016 Lisbon, Portugal

${ }^{2}$ NOVA National School of Public Health, Public Health Research Centre,

Universidade NOVA de Lisboa, Lisbon, Portugal

Full list of author information is available at the end of the article
}

the all-age population, influenza epidemics have been estimated to be associated with an average of 24.7 allcause excess deaths per 100,000 [2] and 19.4 per 100,000 excess pneumonia and influenza hospitalizations [3].

Besides age, the presence of certain medical conditions, namely diabetes, obesity, immunodeficiency and chronic respiratory, cardiovascular, kidney and renal diseases, are well-established risk factors for severe influenza complications such as hospitalizations, intensive care and death [4].

In Portugal, an at-risk based vaccination program has been in place at least since 2001/2002. In accordance with the National Directorate for Health clinical guidelines [5], influenza vaccination is strongly recommended to those at higher risk for influenza complications (chronic and immunocompromised patients older than 6 months of age, pregnant women), as well as those aged

(c) The Author(s). 2019 Open Access This article is distributed under the terms of the Creative Commons Attribution 4.0 International License (http://creativecommons.org/licenses/by/4.0/), which permits unrestricted use, distribution, and reproduction in any medium, provided you give appropriate credit to the original author(s) and the source, provide a link to the Creative Commons license, and indicate if changes were made. The Creative Commons Public Domain Dedication waiver (http://creativecommons.org/publicdomain/zero/1.0/) applies to the data made available in this article, unless otherwise stated. 
65 and over and to institutionalized to whom the vaccine is offered free of charge. Seasonal influenza vaccination is also recommended to health professionals and other caregivers.

Every year seasonal influenza vaccination campaigns with inactivated trivalent vaccine start in early October run throughout the fall and winter. Despite gradual increase in influenza vaccine uptake in the 65 years and older population [6], in Portugal, like in most other European Union (EU), vaccination coverage (VC) still has not reached the target of $75 \%$ set by the World Health Organization and the European Commission (EC) [7]. Individuals with chronic conditions have even lower seasonal influenza vaccine coverage's, that ranged between $32.3 \%$ in $2015 / 16$ and $41.0 \%$ in the $2017 / 18$ season $[8]$.

To increase the acceptability of the vaccine, it is important to quantify the benefits of annual influenza vaccination, namely by estimating its impact at the population level. Influenza vaccine effectiveness (IVE) studies are conducted in Europe every season and allow early and end of season estimates on the reduction of medically attended confirmed influenza infections, either at primary care or hospital level [9-11]. However, population data on influenza-associated outcomes prevented each season by influenza vaccination, in high-risk populations, is scarce. Moreover, measuring the impact of the influenza vaccination strategy every season is methodologically challenging, as influenza vaccination programmes are in place for several decades, which inhibit the before/after comparison of the introduction of this public health intervention. To overcome this, some authors use an ecologic approach that permits the estimation of influenza vaccination impact using data on vaccine coverage, vaccine effectiveness and the number of observed influenza events [12-16].

This study aimed to estimate, the influenza-related hospitalizations and intra-hospital deaths attributable to influenza averted by seasonal influenza vaccination strategy, during the influenza seasons 2014/15 to 2016/17, in individuals 65 years and older and those, at any age, with comorbidity that represents a high risk group for influenza complications.

\section{Methods}

\section{Hospitalization data}

We developed an observational retrospective ecologic study using the National Hospital Discharge Database.

This database covers all public hospitals in Portugal mainland and includes demographic data, diagnosis, procedures, length of stay and discharge outcomes for all episodes of hospital care. In the 2006-2016 period, this database included approximately $79 \%$ of all hospital admissions that occurred in Portugal [17]. Diagnoses and some procedures (laboratory results not included) are coded using the International Classification of Diseases (ICD) - 9th Revision Clinical Modification (ICD-9-CM) version [18] until 1st January 2016 and ICD-10-CM [19] onwards. Final validated databases are available for research after every 9 to 12 months.

\section{Study population}

The target population of this study is high-risk individuals, namely, aged 65 and older or $<65$ years with a chronic condition (diabetes, chronic respiratory, cardiovascular, kidney and renal diseases, obesity, immunodeficiency) for which the influenza vaccine is recommended [20-22]. An individual was considered as having a chronic condition if it was hospitalized and had a secondary diagnosis within a set of chronic conditions presented in Table 1.

To estimate the number of high-risk individuals in Portugal, we used the population estimates from the national statistical office (Statistics Portugal) [23] and the proportion of self-reported chronic conditions in the 0 4 and 15-64 age groups from two health surveys representative at National and regional level $[24,25]$.

\section{Severe influenza-related events}

We considered two severe influenza-related outcomes: hospitalizations (admissions for $>24 \mathrm{~h}$ ) and intrahospital deaths attributable to influenza.

\section{Hospitalizations}

Hospital admissions due to influenza were obtained by multiplying the weekly number of severe acute influenza respiratory illness (SARI) hospitalizations by the weekly proportion of SARI influenza positivity. The proportion of influenza-positive was obtained from the hospitalbased Portuguese laboratory network for the diagnosis of influenza [26].

A SARI hospitalization was defined as an episode with hospital stay length higher than $24 \mathrm{~h}$ with a primary diagnosis coded as any of SARI codes defined in Integrated Monitoring of Vaccines Effects in Europe (IMOVE+) protocol [27] (Table 2).

\section{Deaths}

Intra-hospital deaths attributable to influenza (from this point forward designated as deaths) were estimated using the hospital discharge outcome information. The number of deaths that occurred in patients hospitalized with SARI diagnosis during the study period was multiplied by the proportion of influenza-positive, obtained from the Portuguese laboratory network for the diagnosis of influenza [26]. 
Table 1 List of International Classification of Diseases (ICD) 9th and 10th version codes for chronic conditions

\begin{tabular}{lll}
\hline & ICD 9th version & ICD 10th version \\
\hline Respiratory & $011,490-511,512.8,513-517,518.3$, & A15, J40-47, J60-94, J96, J99, J182, \\
Cardiovascular & $518.8,519.9,714.81$ & M34.81, M05.10 \\
& 746.9 & Q24.9 \\
& $402.0-402.91$ & $111.0-111.9$ \\
& $428.42,428.32,482.22$ & I50.22, I50.32, I50.42 \\
Renal & $412,0-412,9,413.0-413.9,414.0-414.9$ & I25.2, I20.8, I20.1, I20.9, I25.0-125.9 \\
Kidney & $581.0-581-9,585.0-585.9$ & N18, N04 \\
& $571.0-571.9$ & K70, K74, K72.1 \\
Hematologic & 576.2 & D56, D57 \\
Imunocompromised & $282.4,282.5,282.6$ & B20, D80-84, D89.8-9, Z21, Z94 \\
Diabetes mellitus & 042,279, V08, V42 & E10-11; Z94.0-Z94.4, Z94.6-Z94.9 \\
Genetic conditions & 250 & E88.01 \\
Obesity & 273.4 & E66.01, E66.2, E66.9 \\
\hline
\end{tabular}

ICD International Classification of Diseases (ICD)

\section{Study period}

The impact of the influenza vaccine national program was estimated for three seasons, 2014/15, 2015/2016 and 2016/17. For each season the analysis was restricted to the epidemic periods. Epidemic periods were established by the primary care-based Portuguese sentinel influenza surveillance system (Table 3). For each season, the study period comprises the epidemic periods, plus 3 weeks lag as more severe outcomes are expected to occur with delay.

\section{Number of averted severe influenza-related events prevented fraction}

To assess the annual impact of the influenza vaccination programmes we estimated the number of severe influenza-related events (IRE) among the high-risk population averted by vaccination (NAE), the respective disease prevented fraction (PF) and the number of highrisk individuals in the population needed to be vaccinated to avoid one IRE (NNV).

NAE measures the impact of the vaccination program in absolute terms and represents the difference between observed IRE ( $\mathrm{n}$ ) and IRE expected in the absence of the vaccination program $(\mathrm{N})$ and was estimated as:

$$
N A E=\mathrm{N}-\mathrm{n}=\mathrm{n} \cdot \frac{I V E \cdot V C}{1-(V C \cdot I V E)}
$$

where $\mathrm{n}$ - observed IRE, IVE - Influenza vaccine effectiveness, $\mathrm{VC}$ - vaccine coverage (details on the formula available at Additional file 1).

The $\mathrm{PF}$, estimated as $\mathrm{PF}=\mathrm{NAE} /(\mathrm{n}+\mathrm{NAE})$, measures the impact of vaccination in relative terms and represents the proportion of averted IRE out of the number of IRE in the population without influenza vaccination program [12-14, 16, 28].

The number needed to vaccinate was also computed as:

$$
\mathrm{NNV}=1 /(\text { IVE } \cdot \mathrm{N} / \text { Population }) \text {. }
$$

\section{Vaccine coverage (VC)}

The influenza vaccination coverage was estimated using the influenza vaccine coverage monitoring system [6, 29], a population-based survey of a sample of approximately 1000 households from Portugal mainland, selected using random digit dialling of mobile and landline phones. In each household, one individual aged 18 or more is interviewed providing information on his/her vaccination status and the vaccination status of the other household elements. The questionnaire also includes information on chronic conditions. Vaccine coverage was estimated for the population with conditions for which the vaccine is recommended and for the population aged 65 and more years.

\section{Influenza vaccine effectiveness (IVE)}

We used hospital-based meta-analysis type/subtype IVE estimates. IVE among those aged 65 and older and with less than 65 years [30] were weighted by the distribution of circulating influenza type/subtypes virus in each season in Portugal. Reported match/unmatched vaccine information [30] was considered. Data on circulating influenza type/subtypes detected in the hospital settings were obtained from the Portuguese Hospital laboratory network for the influenza diagnosis [26, 31].

Vaccine effectiveness against intra-hospital deaths of 56\% [14 to 77\%] reported by Casado et al. [32] for the Spanish population was used for all high-risk groups. 
Table 2 List of diagnosis codes for which patients could be screened for onset of SARI symptom, IMOVE+ hospital based IVE studies

\begin{tabular}{|c|c|c|c|}
\hline Category & Morbidity & ICD-9 & ICD-10 \\
\hline \multirow[t]{8}{*}{ Influenza like illness } & Cough & 786.2 & R05 \\
\hline & Difficulty breathing & 786.05 & R06 \\
\hline & Sore throat & 784.1 & R07.0 \\
\hline & Dysphagia & 787.20 & R13 \\
\hline & Fever & 780.6 & R50.9 \\
\hline & Headache & 784.0 & R51 \\
\hline & Myalgia & 729.1 & M79.1 \\
\hline & Fatigue/malaise & 780.79 & R53.1, R53.81, R53.83 \\
\hline \multirow[t]{2}{*}{ Cardiovascular diagnosis } & $\begin{array}{l}\text { Acute myocardial infarction or acute coronary } \\
\text { syndrome }\end{array}$ & $\begin{array}{l}410-411,413- \\
414\end{array}$ & $120-23,124-25$ \\
\hline & Heart failure & 428 to 429.0 & 150,151 \\
\hline \multirow[t]{8}{*}{ Respiratory diagnosis } & Emphysema & 492 & J43.9 \\
\hline & Chronic obstructive pulmonary disease & 496 & J44.9 \\
\hline & Asthma & 493 & $J 45$ \\
\hline & Myalgia & 729.1 & M79.1 \\
\hline & Dyspnoea/respiratory abnormality & 786.0 & R06.0 \\
\hline & Respiratory abnormality & 786.00 & R06.9 \\
\hline & Shortness of breath & 786.05 & R06.02 \\
\hline & Other respiratory abnormalities & 786.09 & $\begin{array}{l}\text { R06.00, R06.09, R06.3, } \\
\text { R06.89 }\end{array}$ \\
\hline \multirow[t]{5}{*}{ Infections } & Pneumonia and influenza & $480-488.1$ & J09-J18 \\
\hline & Other acute lower respiratory infections & $466,519.8$ & $J 20-J 22$ \\
\hline & Viral infection, unspecified & 790.8 & B34.9 \\
\hline & Bacterial infection, unspecified & 041.9 & A49.9 \\
\hline & Bronchitis & 490,491 & $J 40,41$ \\
\hline \multirow[t]{2}{*}{ Inflammation } & SIRS non infectious without acute organ dysfunction & 995.93 & R65.10 \\
\hline & SIRS non infectious with acute organ dysfunction & 995.94 & R65.11 \\
\hline \multirow{13}{*}{$\begin{array}{l}\text { Diagnoses related to deterioration of general } \\
\text { condition or functional status }\end{array}$} & General physical deterioration, lethargy, tiredness & 780.79 & R53.1, R53.81, R53.83 \\
\hline & Anorexia & 783.0 & R63.0 \\
\hline & Feeding difficulties & 783.3 & R63.3 \\
\hline & Abnormal weight loss & 783.21 & R63.4 \\
\hline & $\begin{array}{l}\text { Other symptoms and signs concerning food and fluid } \\
\text { intake }\end{array}$ & 783.9 & R63.8 \\
\hline & Desorientation/Altered mental status & 780.97 & R41.0 \\
\hline & Dizziness and giddiness & 780.4 & R42 \\
\hline & Infective delirium & $293.0,293.1$ & F05 \\
\hline & Coma & 780.01 & R40.2 \\
\hline & Transient alteration of awareness & 780.02 & R40.4 \\
\hline & Other alteration of consciousness (Somnolence, stupor) & 780.09 & R40.0, R40.1 \\
\hline & Febrile convulsions (simple), unspecified & 780.31 & R56.00 \\
\hline & Complex febrile convulsions & 780.32 & R56.01 \\
\hline
\end{tabular}

${ }^{a}$ SIRS Systemic inflammatory response syndrome

\section{Uncertainty}

To estimate $95 \%$ confidence intervals for NAE, NNV, and PF we used Monte Carlo simulations (see more detail in Additional file2). We assumed a Poisson distribution for the number of influenza-related events and Normal distributions for $\log (1-\mathrm{IVE})$ and $\log (\mathrm{VC} /(1-\mathrm{VC}))$ [13]. The 
Table 3 Distribution per season of the number of severe acute respiratory infections (SARI) hospitalizations and deaths, SARI Influenza-related hospitalizations and deaths, influenza vaccine effectiveness and vaccine coverage estimates for $\geq 65$ years and $<65$ years with a chronic condition

\begin{tabular}{|c|c|c|c|}
\hline Season features & $2014 / 15$ & $2015 / 16$ & $2016 / 17$ \\
\hline Epidemic period & w1 to w7/2015 & w53/2015 to w7/2016 & $w 48 / 2016$ to $w 1 / 2017$ \\
\hline Dominant type/subtype & $\mathrm{B} / \mathrm{Yam}$ & AH1N1pdm09 & $\mathrm{AH} 3$ \\
\hline \multicolumn{4}{|l|}{ SARI Hospitalizations } \\
\hline$\geq 65$ years $(n)$ & 24,720 & 21,913 & 18,724 \\
\hline Chronic condition (n) & 4379 & 4595 & 3231 \\
\hline \multicolumn{4}{|l|}{ SARI deaths } \\
\hline$\geq 65$ years $(n)$ & 3824 & 3044 & 2942 \\
\hline$<65$ years with a chronic condition (n) & 198 & 196 & 137 \\
\hline \multicolumn{4}{|l|}{ Influenza hospitalizations } \\
\hline$\geq 65$ years & 6742 & 5107 & 6003 \\
\hline$<65$ years with a chronic condition & 1204 & 1069 & 1031 \\
\hline \multicolumn{4}{|l|}{ Influenza deaths } \\
\hline$\geq 65$ years & 1078 & 731 & 909 \\
\hline$<65$ years with a chronic condition & 56 & 47 & 42 \\
\hline \multicolumn{4}{|l|}{ Influenza vaccine effectiveness (IVE \%) } \\
\hline$\geq 65$ years $[95 \% \mathrm{Cl}]$ & $29.0[14.7$ to 43.4$]$ & $49.1[26.4$ to 71.7$]$ & $42.9[33.0$ to 52.8$]$ \\
\hline$<65$ years $[95 \% \mathrm{Cl}]$ & 46.1 [20.9 to 71.3$]$ & $53.0[34.9$ to 71.1$]$ & $58.9[38.1$ to 79.6$]$ \\
\hline \multicolumn{4}{|l|}{ Vaccine coverage (VC \%) } \\
\hline$\geq 65$ years $[95 \% \mathrm{Cl}]$ & $49.8[41.3$ to 58.4$]$ & $50.1[42.1$ to 58.1$]$ & $57.5[50.8$ to 64.1$)$ \\
\hline Chronic condition [95\%Cl] & 34.2 [28.1 to 40.9$]$ & 32.3 [26.8 to 38.4$]$ & 39.7 [33.7 to 45.9$]$ \\
\hline
\end{tabular}

SARI severe acute respiratory infections, $w$ week, IVE influenza vaccine effectiveness, $C I$ confidence intervals, VC vaccine coverage

distributions parameters were derived from respective point estimates and 95\% confidence intervals. We drew 10,000 simulations samples of influenza-related events, IVE and $\mathrm{VC}$ to obtain empirical distributions of NAE, NNV, and PF in each season and average across three seasons. We used the 2.5 and 97.5 percentiles of these empirical distributions as lower and upper limits of the $95 \%$ confidence intervals.

\section{Results}

We estimate that during the study period there were about 3.82 million high-risk individuals in Portugal targeted by the National vaccination program: 2.07 million were aged 65 and more and about 1.75 million aged less than 65 years and had a chronic condition for which the influenza vaccine is recommended.

During the study period, the estimated number of SARI hospitalizations among high-risk individuals ranged from 21,955 (season 2016/17) to 29,099 (season 2014/15) (Table 3). Influenza deaths varied between 778 in season 2015/16 and 1134 in season 2014/15.

The most frequent comorbidities of hospitalized SARI patients were chronic respiratory diseases (46\%), followed by diabetes (32\%) and cardiovascular diseases (24\%). The highest number of influenza-related hospitalizations and deaths was estimated in season 2014/15, a
B/Yamagata dominant season but with $\mathrm{A}(\mathrm{H} 3 \mathrm{~N} 2)$ circulation (7946 hospitalizations and 1134 deaths). Influenza vaccine effectiveness was lower in the 2014/15 season than in the other seasons. Overall, point estimate IVE was lower in the individuals aged 65 and more years than in younger individuals with chronic conditions. In contrast, vaccine coverage was higher in the older population, increasing from $49.8 \%$ in the $2014 / 15$ season to $57.5 \%$ in the $2016 / 17$ season.

On average, per season, the influenza vaccination campaign averted approximately 1833 hospitalizations and 383 deaths in the Portuguese high-risk population (Table 4). The highest number of averted events occurred in the population aged 65 and more years and the $2016 / 17$ season, a season with a predominance of $\mathrm{A}(\mathrm{H} 3 \mathrm{~N} 2)$ virus.

Overall, the vaccination strategy prevented on average, 21 and $18.5 \%$ of influenza hospitalizations in those 65 years and older and under 65 years with chronic conditions, respectively, and $19.5 \%$ and $37.4 \%$ of deaths in the $<65$ years and in the older adult population, respectively. To prevent one influenzarelated hospitalization or death, we would need to vaccinate on average 3360 and 60471 high-risk individuals, respectively. 
Table 4 Estimates of the annual average and seasonal prevented fraction and number of averted influenza hospitalizations and deaths attributed to the vaccine program, for seasons 2014/15 to 2016/17

\begin{tabular}{|c|c|c|c|c|}
\hline \multirow[t]{2}{*}{ IRE } & \multicolumn{3}{|l|}{ Season } & \multirow[t]{2}{*}{ Average } \\
\hline & $2014 / 15$ & 2015/16 & 2016/17 & \\
\hline \multicolumn{5}{|l|}{ Hospitalization } \\
\hline \multicolumn{5}{|l|}{$\geq 65$ years } \\
\hline $\operatorname{NAE}(n)[95 \% \mathrm{Cl}]$ & 1124 [443-1863] & 1644 [460-2799] & 1957 [1326-2657] & $1584[1058-2097]$ \\
\hline PF (\%)[95\%Cl] & $14.3[6.2-21.6]$ & $24.3[8.2-35.4]$ & $24.6[18.1-30.7]$ & $21.0[15.1-26.1]$ \\
\hline NNV (n)[95\%Cl] & 890 [565-2233] & 621 [384-2050] & $616[473-882]$ & $741[553-1426]$ \\
\hline \multicolumn{5}{|c|}{$<65$ years with chronic condition } \\
\hline $\operatorname{NAE}(n)[95 \% C l]$ & $222[42-383]$ & 218 [106-326] & 311 [135-473] & 249 [158-337] \\
\hline PF $(\%)[95 \% \mathrm{Cl}]$ & $15.6[3.3-24.1]$ & $16.9[9.1-23.4]$ & $23.2[11.6-31.5]$ & $18.5[12.5-23.4]$ \\
\hline NNV (n) $[95 \% \mathrm{Cl}]$ & $2657[1628-10,924]$ & 2564 [1857-5172] & 2200 [1540-4957] & 2619 [1921-6015] \\
\hline \multicolumn{5}{|l|}{ Deaths } \\
\hline \multicolumn{5}{|l|}{$\geq 65$ years } \\
\hline $\operatorname{NAE}(n)[95 \% \mathrm{Cl}]$ & $409[81-721]$ & $281[52-489]$ & $427[95-743]$ & 371 [198-541] \\
\hline PF (\%) $[95 \% \mathrm{Cl}]$ & $27.7[7.0-40.1]$ & $27.5[6.7-40.1]$ & $31.9[9.4-45.0]$ & $29.0[18.0-37.4]$ \\
\hline NNV (n) $[95 \% \mathrm{Cl}]$ & $2416[1459-10,267]$ & $3613[2166-15,078]$ & $2796[1633-10,422]$ & $3241[1845-10,141]$ \\
\hline \multicolumn{5}{|c|}{$<65$ years with chronic condition } \\
\hline $\operatorname{NAE}(n)[95 \% \mathrm{Cl}]$ & 13 [3-22] & 10 [2-49] & 12 [3-20] & 12 [6-16] \\
\hline PF (\%)[95\%Cl] & $18.9[4.8-27.9]$ & $17.9[4.3-26.1]$ & $22.0[6.5-31.7]$ & $19.5[11.8-25.4]$ \\
\hline NNV (n) $[95 \% \mathrm{Cl}]$ & $45,211[29,413-176,520]$ & $54,149[35,348-205,119]$ & $58,216[37,146-206,237]$ & $57,230[37,610-176,457]$ \\
\hline
\end{tabular}

IRE influenza related event, NAE number of averted events, $C l$ confidence interval, $P F$ prevented fraction, NNV number needed to vaccinate

\section{Discussion}

We estimated that during the influenza seasons 2014/15, 2015/16 and 2016/17, the trivalent inactivated seasonal influenza vaccination strategy averted each season, on average, more than 1830 hospitalizations and 380 deaths in the high-risk population in Portugal.

Overall, the impact of the program was higher in the population aged 65 and more years, a sub-group with higher VC but systematically lower IVE, in which it accounted for 86 and $95 \%$ of the total number of averted hospitalizations and deaths. These results reflect not only the higher risk of complication of that population but also the potential gain that could be achieved by increasing the vaccine coverage. In seasons with lower influenza vaccine, performance high vaccine coverage could balance and allow reasonable prevented fraction. Also, it demonstrate that, even with limited effectiveness, the influenza vaccination program prevented a considerable number of hospitalizations and deaths associated with influenza in the 65 years and older population.

The results also show that, even in seasons with a mismatch, between circulating virus and vaccine composition, like the 2014/15 season, vaccinating this high-risk group of individuals averted 1346 hospitalizations and 264 deaths. This included averting $5 \%$ premature deaths of individuals aged $<65$ years. The highest number of averted events occurred in the $\mathrm{A}(\mathrm{H} 3 \mathrm{~N} 2)$ dominant $2016 / 17$ season, where approximately 2268 hospitalizations and 442 deaths were prevented. These results are important given that in seasons with $\mathrm{A}(\mathrm{H} 3 \mathrm{~N} 2)$ predominant circulation i) a considerable burden of influenza is observed in the target vaccination subgroup and ii) vaccine effectiveness tends to be low against this virus sub-type [30, 33]. Besides, in seasons with $\mathrm{A}(\mathrm{H} 3 \mathrm{~N} 2)$ predominance, the influenza vaccination impact is limited in preventing primary care consultations by influenza [34] and thus this result reinforces the main objective of the influenza vaccination strategy as the reduction of severe complications by influenza.

The estimated prevented fractions indicate that on average, per season, the influenza vaccination strategy prevented $21 \%$ of the hospitalization in the population aged 65 and more and $18.5 \%$ in the $<65$ years with a chronic condition. Season specific estimates in $2015 / 16$ season $(P F=24.3 \%$ ) was comparable to estimates obtained in a study for the USA population for the same season $(22.5,95 \%$ CI: $13.5-$ 31.4) [35] and were also comparable to estimates reported for the USA population in other seasons with predominant circulation of $\mathrm{A}(\mathrm{H} 1) \mathrm{pdm} 09$ virus [36]. However, for the 2014/15 and 2016/17 season, our estimates were higher than the reported for the USA. For instance, it was double than the $7 \%$ estimates published for the $2014 / 15$ season $[15,37]$ and $11.5 \%$ estimates for the $2016 / 17$ season [38]. Considering that the PF mainly depends on the VC and IVE 
estimates [39] and that VC was comparable between countries and was stable along the period in study, the main contributor to the observed differences was most probably IVE. In our study, we used type/subtype specific meta-analysis estimates and weighed to account for the virus in circulation. In the 2014/15 season, although the mismatched $\mathrm{A}(\mathrm{H} 3 \mathrm{~N} 2)$ virus circulated in Portugal, the predominant virus was type B virus [40]. As such, season-specific IVE for $2014 / 15$ season was estimated to be $29 \%$ in the more than 65 years population and $46 \%$ in the ones with chronic conditions, thus justifying the increased estimated PF. In the 2016/17 season, the predominant $\mathrm{A}(\mathrm{H} 3 \mathrm{~N} 2)$ in Portugal matched the vaccine strain and this study final IVE estimates for the population aged 65 and more were considerably higher than the $17 \%$ published in Europe [41] and 20\% in the USA [38].

Concerning the most severe outcome, we estimate that $19.5 \%$ or $29 \%$ of hospitalized influenza deaths were prevented by the vaccination strategy. The comparison with other studies is limited as most studies focus on older adults and all-cause mortality [16] or cause-specific mortality outcomes $[13,15]$. Nevertheless, and though using a conservative estimate of $56 \%$ reduction of influenzarelated intra-hospital deaths, we estimate that the vaccination strategy would prevent premature deaths in < 65 years population with chronic conditions.

To prevent one hospitalization or death we would need to vaccinate additionally 3982 individuals aged 65 and more years and 59,849 individuals with chronic conditions. These results indicate that there is a potential increased benefit if the $75 \% \mathrm{VC}$ target would be achieved.

The results presented should be interpreted in light of the study's limitations. The ecologic nature of the study and the use of several data sources limits the study external validity.

In relation to the study design, the main objective of the study is to measure the impact of the influenza vaccination programme and this is methodologically challenging. For some infectious diseases, as pneumococcal pneumonia, the impact of vaccination in the older adult Portuguese population was measured by comparing hospitalizations rate before and after the introduction of the pneumococcal conjugated vaccines [42]. However, for influenza vaccination, with a vaccination programme in place for long time, such approach is not feasible. The method that we used to estimate the influenza vaccination strategy impact has been used by several countries $[12-16,28]$ and consists in evaluating how the vaccination programme works at population level, using as reference an hypothetical totally susceptible population that has never been exposed to the intervention.

The methods measure only the direct effect of vaccination in the population and thus represents a more conservative estimate of the impact as does not account for indirect effects. Also, there are some limitations to the data. First, hospitalization and deaths were retrieved from a hospital discharge database collected for administrative and hospital financing purposes, which covers approximately $79 \%$ of the national hospitalizations [17]. Another limitation of this database to estimate the impact in each season is the time to have available data. The hospitals are in the process of changing from ICD9 to ICD10 and this has delayed obtaining the final database jeopardizing the use of annual estimation of vaccination strategy impact to prepare the next season. Finally, this database includes diagnoses and some procedures codes, however, laboratory results are not systematically done nor available which prohibit the use of influenza laboratory diagnoses directly from it. This limitation had as consequence the need of using an external database (from the hospital-based Portuguese laboratory network for the diagnosis of influenza) to obtain an estimate of the influenza hospitalized cases.

In our study, the VC was obtained from self-reported data and restricted to non-institutionalized Portuguese mainland residents. Given that VC is higher in the institutionalized population, our $\mathrm{VC}$ results may be underestimated and thus underestimation of impact results. Finally, IVE against mortality may not represent the Portuguese population, since we used VE derived from a study in a population from Spain that could have a different distribution of chronic conditions and access to health care. Also, the same estimate was used for all seasons and sub-group of population and IVE is expected to vary between seasons and in younger individuals.

The study has also considerable strengths. First, to our knowledge, this is the first attempt to measure the vaccination impact in a population $<65$ years with chronic conditions. Considering that this subgroup is targeted by influenza vaccination programs and is an important fraction of the population (26.2\% of population aged 15-64 years) our results demonstrate important benefits by the seasonal vaccination in this sub-group. In a country with low seasonal adherence to influenza vaccine uptake in the group of the population with a chronic condition for which seasonal influenza vaccination is recommended [43], this information could be important to increase vaccine coverage in this target group. Second, we used an alternative method to estimate influenza severe burden in Portugal to better fit the impact study. Given the ecologic nature of the adopted approach, it was important to have specific outcomes and also that had correspondence to the outcome of IVE estimates.

Previous research in Portugal provided estimates of influenza excess associated hospitalizations [3] and all-cause deaths [2] that were based on time series approaches. Although these methods are more comprehensive approaches and often used to measure influenza burden [44], in our case, it was important to use specific influenza-related outcomes for impact estimation. We 
used hospitalized SARI and intra-hospital deaths, restricted to epidemic periods, to improve specificity. Also, it was important to have an outcome that was highly correlated with IVE estimates. Finally, to increase external validity we used i) a national discharge database, ii) an influenza laboratory diagnoses database that collects influenza positivity results from hospitals distributed at national level; iii) influenza vaccine effectiveness from meta-analysis and iv) vaccine coverage estimates from a population-based survey. Moreover, to reduce potential heterogeneity related to different codification procedures, the study was restricted to only 3 seasons, but that with different pattern of the influenza virus circulation. All these using registry/monitoring data easily accessible that can be replicable each season. Following the example of the USA [45], these results, along with the burden and effectiveness results can be reported, so to better communicate the influenza vaccination benefits.

\section{Conclusion}

The influenza vaccination strategy in place in Portugal for the 65 and more years individuals and individuals with chronic conditions, prevented on average 1833 hospitalizations and 383 deaths per season. The applied method identified and quantified the overall benefits of the influenza vaccination program, even in seasons with limited vaccine effectiveness. Also, it captured the impact of several outcomes with different levels of severity.

Given the already mentioned, multiple data source ecological nature of the study; further investigations are warranted, with the perspective of evaluating the sensibility of the approach in other seasons, countries and data sources.

The knowledge on health benefits in terms of influenzarelated hospitalizations and deaths averted by the vaccination program will allow better understanding the impact of the national vaccination strategies and strengthening public health communication with the general public and policymakers, to support public health plans towards the increase of vaccine coverage in high-risk groups.

\section{Supplementary information}

Supplementary information accompanies this paper at https://doi.org/10. 1186/s12889-019-7958-8.

Additional file 1. Deduction of the formulas of number of averted events (NAE) and number needed to vaccinate (NNV).

Additional file 2. Construction of empirical distributions for number of influenza-related events, vaccine coverage (VC) and influenza vaccine effectiveness (IVE) and estimation of confidence intervals for number of averted events (NAE), prevented fraction (PF) and number needed to vaccinate (NNV)

\section{Abbreviations}

Cl: Confidence Interval; EU: European Union; ICD: International Classification of Diseases; IRE: Influenza-Related events; IVE: Influenza Vaccine Effectiveness;
NAE: Number of Averted Events; NNV: Number Needed to Vaccinate; PF: Prevented Fraction; SARI: Severe Acute Respiratory IIIness; VC: Vaccine Coverage

\section{Acknowledgements}

The authors would like to acknowledge the Portuguese Laboratory Network for the Diagnosis of Influenza for providing hospital-based data on influenza diagnostics. We would also like to acknowledge MD Ricardo Alves for the clinical support in target group codification.

\section{Authors' contributions}

AM designed, planned the study, interpreted results and wrote the original draft of the manuscript. IK extracted and analysed all the data and was a major contributor in writing the manuscript. $\mathrm{AL}, \mathrm{CMD}$ and $\mathrm{BN}$ collaborated in conceptualization of the study and the interpretation of results and critically reviewed the manuscript. All authors read and approved the final version of the manuscript.

\section{Funding}

Activities related to individuals aged 65 and more years were supported by European Commission Horizon 2020 programme [grant agreement No 634446]. The funding body had no role in the design, collection, analysis, and interpretation of data and or in writing the manuscript.

\section{Availability of data and materials}

The Hospital Discharge dataset is not publicly available. The Health Systems Central Administration (Administração Central do Sistema de Saúde, ACSS) provides the Hospital Discharge dataset to the National Health Institute in a regular basis. This dataset is anonymized and may be used for epidemiological studies. The aggregated data used in this specific study is available from the corresponding author upon reasonable request.

\section{Ethics approval and consent to participate}

This study corresponds to a secondary data analysis of the Hospital Discharge dataset, which is collected by the Health Systems Central Administration (Administração Central do Sistema de Saúde, ACSS). The ACSS provides anonymized data for epidemiological research. The anonymization implies the removal of any personal data. According to the National Ethics Committee for Clinical Research "Personal data that has been rendered anonymous in such a way that the person is not or no longer identifiable is no longer considered personal data and is therefore not covered by article 3 of the General Data Protection Regulation" (https:// www.ceic.pt/documents/20727/57550/RGPD/d48e1ec0-39bd-437e-96ca-ffd74 0c8b732 - page 2). For this reason the study protocol was not submitted to an ethical committee.

\section{Consent for publication}

Not applicable.

\section{Competing interests}

The authors declare that they have no competing interests.

\section{Author details}

${ }^{1}$ Departamento de Epidemiologia, Instituto Nacional de Saúde Doutor Ricardo Jorge, Av. Padre Cruz, 1649-016 Lisbon, Portugal. ${ }^{2}$ NOVA National School of Public Health, Public Health Research Centre, Universidade NOVA de Lisboa, Lisbon, Portugal. ${ }^{3}$ National Centre of Epidemiology, Institute of Health Carlos III CIBER de Epidemiología y Salud Pública (CIBERESP), Madrid, Spain.

Received: 18 July 2019 Accepted: 18 November 2019 Published online: 16 December 2019

\section{References}

1. Iuliano AD, Roguski KM, Chang HH, Muscatello DJ, Palekar R, Tempia S, et al. Estimates of global seasonal influenza-associated respiratory mortality: a modelling study. Lancet. 2018;391(10127).

2. Nunes B, Viboud C, Machado A, Ringholz C, Rebelo-de-Andrade H, Nogueira $P$, et al. Excess mortality associated with influenza epidemics in Portugal, 1980 to 2004. PLoS One. 2011;6(6):e20661. 
3. Rodrigues E, Machado A, Silva S, Nunes B. Excess pneumonia and influenza hospitalizations associated with influenza epidemics in Portugal from season 1998/1999 to 2014/2015. Influenza Other Respir Viruses. 2018;12(1): 153-60.

4. Coleman BL, Fadel SA, Fitzpatrick T, Thomas SM. Risk factors for serious outcomes associated with influenza illness in high- versus low- and middleincome countries: systematic literature review and meta-analysis. Influenza Other Respir Viruses. 2018;12(1):22-9.

5. Direção Geral de Saúde. Orientação da Direção-Geral da Saúde. Vacina contra a gripe. Época 2017-2018. 2018;1-6.

6. Machado A, Kislaya I, Santos AJ, Nunes B. Vacinação antigripal da população portuguesa:18 anos de evolução da cobertura e os fatores associados a toma da vacina. 2017 [cited 8 Sep 2018 ];1-42. Available from: http:// repositorio.insa.pt//handle/10400.18/5392

7. Mereckiene J, Cotter S, Nicoll A, Lopalco P, Noori T, Weber JT, et al. Seasonal influenza immunisation in Europe. Overview of recommendations and vaccination coverage for three seasons: Prepandemic (2008/09), pandemic (2009/10) and post-pandemic (2010/11). Eurosurveillance. 2014;19(16):20780.

8. Machado A, Torres AR, Kislaya I, Neto M. Vacinação antigripal da população portuguesa nas épocas 2016/2017 e 2017/2018: cobertura e características do ato vacinal. 2018; Available from: http://hdl.handle.net/10400.18/5700

9. Kissling $E$, Valenciano $M$. Early influenza vaccine effectiveness results 2015-16: I-MOVE multicentre case-control study, vol. 21. Sweden: Eurosurveillance; 2016.

10. Kissling E, Rondy M, Kaić B, Horváth JK, Ferenczi A, Oroszi B, et al. Early 2016/17 vaccine effectiveness estimates against influenza A(H3N2): I-move multicentre case control studies at primary care and hospital levels in Europe. Eurosurveillance. 2017;22(7).

11. Rondy M, Kissling E, Emborg H-D, Gherasim A, Pebody R, Trebbien R, et al. Interim 2017/18 influenza seasonal vaccine effectiveness: Combined results from five European studies. Eurosurveillance. 2018;23(9).

12. Kostova D, Reed C, Finelli L, Cheng P-Y, Gargiullo PM, Shay DK, et al. Influenza IIIness and Hospitalizations Averted by Influenza Vaccination in the United States, 2005-2011. Goldstein E, editor. PLoS One. 2013;8(6):e66312.

13. Foppa IM, Cheng P-Y, Reynolds SB, Shay DK, Carias C, Bresee JS, et al. Deaths averted by influenza vaccination in the U.S. during the seasons 2005/06 through 2013/14. Vaccine. 2015:33(26):3003-9.

14. Jackson ML, Jackson LA, Kieke B, McClure D, Gaglani M, Murthy K, et al. Incidence of medically attended influenza infection and cases averted by vaccination, 2011/2012 and 2012/2013 influenza seasons. Vaccine. 2015; 33(39):5181-7.

15. Rolfes MA, Foppa IM, Garg S, Flannery B, Brammer L, Singleton JA, et al. Annual estimates of the burden of seasonal influenza in the United States: a tool for strengthening influenza surveillance and preparedness. Influenza Other Respir Viruses. 2018 Jan;12(1):132-7.

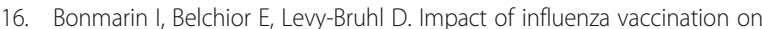
mortality in the French elderly population during the 2000-2009 period. Vaccine. 2015;33(9):1099-101.

17. Statistics Portugal. World Health Day - 7 April. Public sector hospitals remain the main providers of health care, despite the strong increase of the private sector [Internet]. 2018. Available from: https://www.ine.pt/xportal/ xmain?xpid=|NE\&xpgid=ine_destaques\&DESTAQUESdest_boui=313635671 \&DESTAQUESmodo=2\&xlang=en.

18. International Classification of Diseases, 9th Revision - Clinical Modification. www.cdc.gov/nchs/icd/icd9.htm.

19. World Health Organization. International Classification of Diseases - 10 th version. 2016. Available at https://icd.who.int/browse10/2016/en.

20. Direção Geral da Saúde. Orientação no 016/2014, de 24/09/2014. Vacinação contra a gripe com a vacina trivalente para a época 2014/2015. Lisboa; 2014. Available at https://www.dgs.pt/directrizes-da-dgs/orientacoes-ecirculares-informativas/orientacao-n-0162014-de-24092014-pdf.aspx.

21. Direção Geral da Saúde. Orientação no 004/2016 Vacinação contra a gripe época 2016/17. Lisboa; 2016. Available at https://www.dgs.pt/upload/ membro.id/ficheiros/i022862.pdf.

22. Direção Geral de Saúde. Orientação no 012/2013 de 25/09/2013 - Vacinação contra a gripe com a vacina trivalente para a época 2013/2014. Lisboa, Portugal; 2013.

23. Instituto Nacional de Estatística. População residente $\left(\mathrm{N}^{\circ}{ }^{\circ}\right)$ por Local de residência (NUTS - 2013), Sexo e Grupo etário; Anual - INE, Estimativas anuais da população residente. [cited 10 sep 2018]. Available at https://
www.ine.pt/xportal/xmain?xpid=INE\&xpgid=ine_indicadores\&indOcorrCod= $0008273 \&$ xlang $=e n$.

24. Torres AR, Machado A, Neto M. ECOS 2018: $1^{\text {a }}$ vaga. Lisboa: Relatório metodológico e de execução; 2018.

25. Instituto Nacional de Estatística, Instituto Nacional de Saúde Dr. Ricardo Jorge. Inquérito Nacional de Saúde 2014. INE; 2014.

26. Guiomar R, Pechirra P, Cristóvão P, Costa I, Conde P, Rodrigues AP, et al Programa Nacional de Vigilância da Gripe: relatório da época 2015/2016. 2016 [cited 8 Sep 2018];1-100. Available from: http://repositorio.insa.pt/ handle/10400.18/4044

27. Seyler T, Rondy M, Valenciano M MA. Protocol for hospital-based case control studies to measure seasonal influenza vaccine effectiveness against laboratory confirmed influenza hospitalisations across the European Union and European Economic Area Member States. Paris, Epiconcept; 2014. Available at https://sites.google.com/site/epiflu/docu.

28. Jackson ML, Phillips CH, Benoit J, Jackson LA, Gaglani M, Murthy K, et al. Burden of medically attended influenza infection and cases averted by vaccination - United States, 2013/14 through 2015/16 influenza seasons. Vaccine. 2018;36(4):467-72.

29. Departamento de Epidemiologia. Dossier ECOS - Em Casa Observamos Saúde. Lisboa; Instituto Nacional de Saúde Doutor Ricardo Jorge, IP. 2010. Available at http://repositorio.insa.pt/handle/10400.18/2590.

30. Rondy M, El Omeiri N, Thompson MG, Levêque A, Moren A, Sullivan SG. Effectiveness of influenza vaccines in preventing severe influenza illness among adults: A systematic review and meta-analysis of test-negative design case-control studies. J Infect. 2017;75:381-94.

31. Guiomar R, Pechirra P, Cristóvão P, Costa I, Conde P, Rodrigues AP, et al. Programa Nacional de Vigilância da Gripe: relatório da época 2016/2017. 2017 [cited 8 Sep 2018];1-95. Available from: http://repositorio.insa.pt/ handle/10400.18/4797

32. Casado I, Domínguez Á, Toledo D, Chamorro J, Astray J, Egurrola M, et al. Repeated influenza vaccination for preventing severe and fatal influenza infection in older adults: a multicentre case-control study. CMAJ. 2018;190(1):E3-12.

33. Belongia EA, Simpson MD, King JP, Sundaram ME, Kelley NS, Osterholm MT, et al. Variable influenza vaccine effectiveness by subtype: a systematic review and meta-analysis of test-negative design studies. Lancet Infect Dis. 2016 Aug;16(8):942-51.

34. Mazagatos C, Machado A, Dijkstra F, Kissling E, Larrauri A, Kislaya I, et al. Measuring the impact of influenza vaccination programmes among the elderly population in Spain, the Netherlands and Portugal, 2015-2018. In: Rath B, Penttinen P, editors. Incidence, Severity and Impact of Influenza. Stockholm: European Centre for Disease Prevention and Control (ECDC); 2019. p. 44.

35. Rolfes MA, Foppa IM, Garg S, Flannery B, Brammer L, Singleton JA, et al. Estimated Influenza Illnessses, Medical Visits, Hospitalizations, and Deaths Averted by Vaccination in the United States [Internet]. In: Centers for Disease Control and Prevention, National Center for Immunization and Respiratory Diseases (NCIRD). 2016. Available from: https://www.cdc.gov/flu/ about/disease/2015-16.htm.

36. Reed C, Kim IK, Singleton JA, Chaves SS, Flannery B, Finelli L, et al. Estimated influenza illnesses and hospitalizations averted by influenza vaccination United States, 2013-14 Influenza Season. MMWR Morb Mortal Wkly Rep. 2014:14:481-4.

37. Centers for Disease Control and Prevention. Estimated Influenza Illnesses and Hospitalizations Averted by Influenza Vaccination-United States, 201213 Influenza Season. MMWR, 2013;62(49);997-1000. Available at https:// www.cdc.gov/mmwr/preview/mmwrhtml/mm6249a2.htm.

38. Estimated Influenza IIInesses and Hospitalizations Averted by Vaccination United States, 2014-15 Influenza Season | Seasonal Influenza (Flu) | CDC [Internet]. CDC. 2017 Available from: https://www.cdc.gov/flu/about/ disease/2014-15.htm [cited 20 Sep 2018]

39. Hanquet $G$, Valenciano M, Simondon F, Moren A. Vaccine effects and impact of vaccination programmes in post-licensure studies. Vaccine [Internet]. 2013;31(48):5634-42 Available from: https://linkinghub.elsevier. com/retrieve/pii/S0264410X13009274[cited 7 Oct 2019].

40. Guiomar R, Costa I, Cristovão P, Pechirra P, Rodrigues AP, Nunes B. Programa Nacional de Vigilância da Gripe: relatório da época 2014/2015; 2015

41. Rondy M, Gherasim A, Casado I, Launay O, Rizzo C, Pitigoi D, et al. Low 2016/17 season vaccine effectiveness against hospitalised influenza $A(H 3 N 2)$ 
among elderly: Awareness warranted for 2017/18 season. Eurosurveillance. 2017;22(41).

42. Kislaya I, Rodrigues AP, Sousa-Uva M, Gómez V, Gonçalves P, Froes F, et al. Indirect effect of 7-valent and 13-valent pneumococcal conjugated vaccines on pneumococcal pneumonia hospitalizations in elderly. Goldstein E, editor. PLoS One [Internet]. 2019;14(1):e0209428. Available from: http://www.ncbi. nlm.nih.gov/pubmed/30650091 [cited 7 Oct 2019].

43. Machado A, Kislaya I, Santos AJ, Gaio V, Gil AP, Barreto M, et al. Factors associated to repeated influenza vaccination in the Portuguese adults with chronic conditions. Vaccine. 2018;36(35):5265-72.

44. Thomas RE. Are influenza-associated morbidity and mortality estimates for those $\geq 65$ in statistical databases accurate, and an appropriate test of influenza vaccine effectiveness? Vaccine. 2014;32(51):6884-901.

45. Centers for Disease Control and Prevention (CDC). National Center for Immunization and Respiratory Diseases (NCIRD). Estimated Influenza IIInesses, Medical visits, and Hospitalizations Averted by Vaccination. 2019. Available at https://www.cdc.gov/flu/vaccines-work/burden-averted.htm.

\section{Publisher's Note}

Springer Nature remains neutral with regard to jurisdictional claims in published maps and institutional affiliations.

Ready to submit your research? Choose BMC and benefit from:

- fast, convenient online submission

- thorough peer review by experienced researchers in your field

- rapid publication on acceptance

- support for research data, including large and complex data types

- gold Open Access which fosters wider collaboration and increased citations

- maximum visibility for your research: over $100 \mathrm{M}$ website views per year

At $\mathrm{BMC}$, research is always in progress.

Learn more biomedcentral.com/submissions 